\title{
Enhancing Community Livelihoods through Nature Based Enterprises: Case of Matinyani Women Group, Kitui, Kenya
}

\author{
Rose Chiteva ${ }^{*}$, Oscar Mayunzu, Moses Lukibisi, Norman Wachira \\ Forest Products Research Centre, Kenya Forestry Research Institute (KEFRI), Kenya
}

Copyright (C) 2016 by authors, all rights reserved. Authors agree that this article remains permanently open access under the terms of the Creative Commons Attribution License 4.0 International License

\begin{abstract}
Nature based Enterprises are ventures that can be exploited to support biodiversity utilization, conservation and equitable benefit sharing from derived resources. This paper highlights the potential of nature based enterprises in enhancing community livelihoods in Kenya, with specific emphasis on Matinyani Enterprise in Kitui, Kenya. The group with a membership of 60 received both theory and hands-on training by Kenya Forestry Research Institute scientistsin product development, setting up and registering an enterprise in 2010 with the Ministry of Sports, Culture and Arts. The training included propagation, processing and value addition of Tamarindus indica fruit jam, juice and wine. Monitoring is frequently done by scientists to ensure adherence to Kenya Bureau of Standards regulations and to maintain the quality of products. There are various indicators of adoptability of the technologies and improved livelihood among these group members; increased awareness of sustainable utilization and conservation of indigenous fruit trees, value added indigenous fruit products being sold locally and a small saving scheme "merry go - round'. There is still a challenge in adoptability of the propagation techniques due to the long periods indigenous fruits take to mature. There is, therefore, need for research to be fast tracked in this area.
\end{abstract}

Keywords Nature Based Enterprises, Livelihood, Kitui, Kenya

\section{Introduction}

Nature based Enterprises (NBEs) are ventures that can be exploited to support biodiversity utilization, conservation and equitable benefit sharing from derived resources. This qualifies them as green businesses that have the dual potential of conservation and income generation to the local communities. Thus, expanding nature-based enterprises can increase income for the rural poor and also develop their resilience to social and environmental threats such as climate change. The importance of an enterprise as a principle source of employment cannot be overstated. Economic growth is fuelled, first and foremost by the creativity and hard work of entrepreneurs and workers [1].

In Kenya, about $79 \%$ of the population lives in rural areas and relies on agriculture for most of its income with the majority being poor, or unable to meet their daily nutritional requirements. Although in some respects conditions have improved since the early $1980 \mathrm{~s}$, the poverty rate has remained steady at about 48 per cent [2]. Though threats such as climate change and ecosystem degradation are beginning to strain those livelihoods, it is widely accepted that the poverty of forest-adjacent communities is a root cause of much forest degradation. Poverty, combined with inadequate forest protection, leads to over-exploitation of "free" forest resources (fuel wood, pole-wood and Non Timber Forest Products) and to illegal activities (poaching for timber, carving wood and game-meat). It also restricts the ability of forest-adjacent communities to think beyond immediate needs, making them unreceptive to forest conservation messages. Sustainable Income-Generating Activities (IGAs) for local communities have therefore become a standard feature of forest conservation projects throughout the developing world [3].

Forest conservation Income generating Activities (IGAs) can be clustered into three categories: 1) enterprises that depend on the continued existence of the forest; 2) plant/tree-based enterprises that may or may not depend on the forest; and 3) enterprises that are completely independent of the forest. The first category includes activities such as ecotourism, apiculture, seed collection, gum and resin collection and butterfly farming. Such IGAs add conservation value to poverty alleviation by building local and political support for conserving the forests [4]. The second category typically involves agroforestry, woodlots, Aloes, indigenous fruits, sericulture, beadwork and the cultivation of medicinal plants, with conservation spin-offs 
through forest product substitution, forest rehabilitation and buffer zone development. The third has benefits in terms of public relations with the local communities and the diversification of livelihood options, reducing vulnerability to environmental and economic shocks.

Tamarind or Tamarindus indica L. of the Fabaceae, sub family Caesalpiniadae, is an important food in the tropics and also accounts for the IGAs. It is a multipurpose tree of which almost every part finds at least some use [5]. Tamarind is indigenous to tropical Africa but has been introduced and naturalized worldwide in over 50 countries. The major production areas are in the Asian countries India and Thailand, but also in Bangladesh, Sri Lanka and Indonesia [6]. In America, Mexico and Costa Rica are the biggest producers. Africa on the whole does not produce Tamarind on commercial scale, though it is widely used by the local people. Minor producing countries in Africa are Senegal, Kenya, Gambia, Tanzania and Zambia [7].

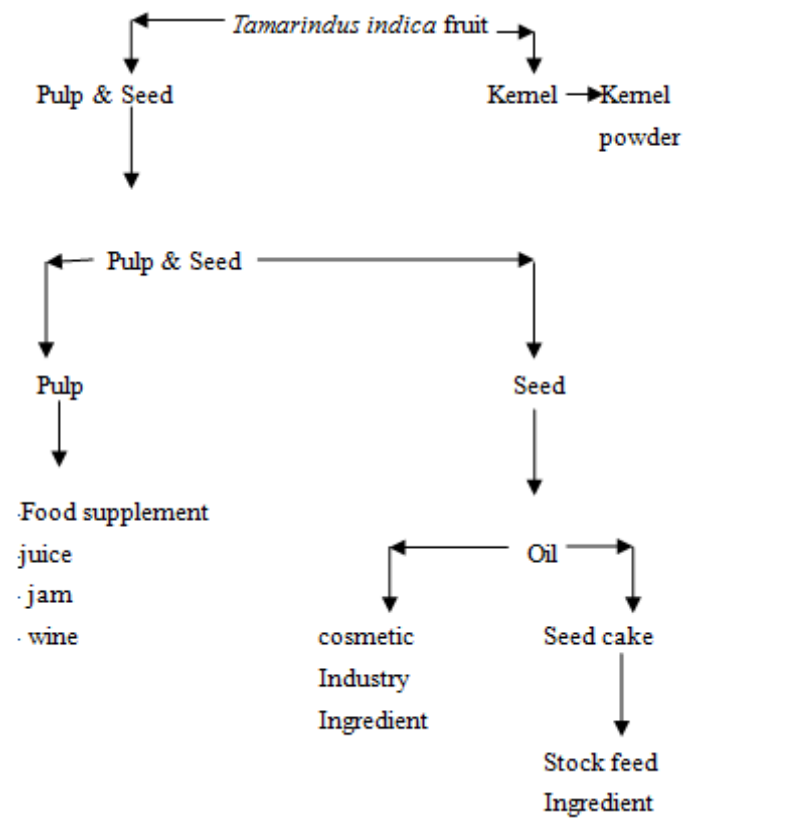

Figure 1. T. indica product flow chart
The T.indica has been widely used to make many products for centuries among them herbal medicine and as a foodstuff (Figure 1). Recognized for stimulation of skin repair, it also assists in environmental skin protection and for premature ageing of the skin. The moisturizing ability of the tamarind has shown to be equal to Hyaluronic Acid in effectiveness and is plant based. T. indica has a natural anti-oxidant Vitamin $\mathrm{C}$ which shields skin from damage due to free radicals from the sun and pollutants. It helps cleanse \& exfoliate the skin to feel refreshed, smooth, and supple. Equally, it helps $\mathrm{pH}$ balance, clarify and brighten skin.

Matinyani Enterprise in Kitui, Kenya is a group with a membership of 60 people who had the objective of generating an income from locally available resources like $T$. indica fruits to alleviate rural poverty. They set up and registered their Enterprise in 2010 with the Ministry of Sports, Culture and Arts. The group has received both theory and hands - on training from Kenya Forestry Research Institute (KEFRI) in indigenous fruit product development. The training includes; propagation, processing and value addition of $T$. indica fruit jam, juice and wine.

There are various indicators of adoptability of the technologies and improved livelihood among these group members; more children are now attending school as opposed to young girls being seen taking care of their siblings and boys herding cows. There is increased awareness of sustainable utilization and conservation of Indigenous Fruit Trees (IFTs), Value added indigenous fruit products being sold locally having been accepted by the consumers and preferred over established brands, and a small saving scheme "merry go - round'. The jam and juice are now included in the market chains especially in the rural areas and the group started generating income by marketing products nationally. Market research indicates that quality product(s) with good packaging have both local and national markets. Quality has been typically regarded as a key strategic component of competitive advantage, and therefore improving product quality has been a matter of prime concern to firms [8]. 


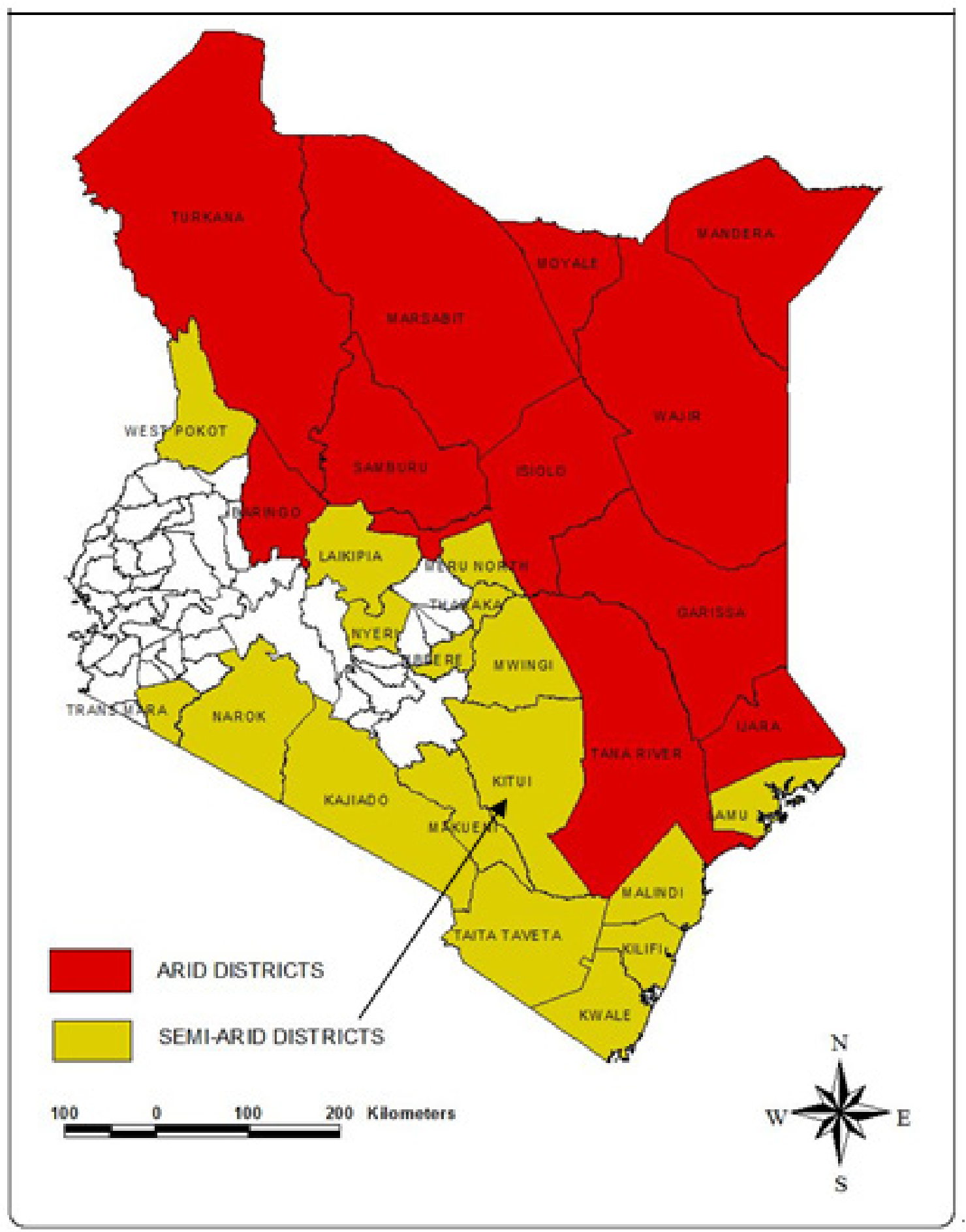

Source: Arid lands Resource management project

Figure 2. Map of Kenya showing Kitui County

Kitui is found in the semi - arid part of Eastern Kenya (Figure 2). The County's temperatures range from a minimum of $14^{\circ} \mathrm{C}$ to a maximum of $34^{\circ} \mathrm{C}$. The rainfall ranges from $500 \mathrm{~mm}$ to $1050 \mathrm{~mm}$ per annum in different parts of the county. Poverty levels stand at $63 \%$. The natural resources include arable land, wildlife, livestock, forest and miner.

Nature based enterprises increase "environmental income" thus stabilizing the household economies of the poor, translating into better nutrition and health, greater access to education, more opportunities for saving and investment and reduced vulnerability to financial shocks. Social gains, as the poor assume greater power to manage local ecosystems and become more active players in the local economy. These gains are often associated with an increased voice in resource decisions and greater equity in the 
distribution of economic benefits from Natural resources [9].

An example of NBEs in Kenya is Parks beyond Parks formed by the Kenya wildlife Service. This is an institutionalization of a structure to support nature-based community enterprises not only an effective tool for managing relationships between people and wildlife, but also a sustainable source of livelihood for communities in wildlife areas [10]. C. Seixas and P. Berkes (year) reported that a diverse variety of partners are needed to help satisfy a diversity of needs, and highlight the importance of networks and support groups in the evolution of commons institutions [11]. African Wildlife Conservation has adopted Conservation enterprise which is a Community-based natural resource management (CBNRM) that recognizes that, local communities are often best placed to conserve natural resources, as long as they stand to gain more than they lose from doing so. Conservation enterprises-commercial activities generating economic and social benefits in ways that help meet conservation objectives - seek to reinforce these incentives [12].

This paper highlights the role that a nature based enterprise has played in improving livelihoods among communities in Kitui. T. indica fruit (Chart 1) was selected as a result of species prioritization by [13] and [14].

\section{Materials and Methods}

Consultations were done with other organizations involved in Nature Based Enterprises e.g. World Agro-forestry Centre, Kenya Forest Service, African Biodiversity Conservation and Innovation Centre, resource users, local resource managers and those involved in income generation from Natural resource trading and processing. Literature review was also used to gather information on NBEs.

\subsection{Case Study: Setting Up Matinyani Enterprise Group}

In setting up the Nature based Enterprise (Tamarinds fruit products) by Matinyani group, an assessment with the help of group members, available resources were established and available services and facilities, potential customers, personal resources (financial, equipment, etc) were identified. In addition, personal skills and those of other family members in relation to desired customer experiences were assessed. With this information, an interest groups/enterprise was formed and registered with the Ministry of Sports, Culture and Arts. The group's capacity was then built in processing, value addition and marketing of Tamarinds fruit products

Working with the group that has Customer Experience, we identified a proper business location that would meet the potential customer's needs in terms of accessibility and using the Service Concept, the potential Tamarinds products were identified by the group. This included; Jam, juice and wine.
This was followed by a Business Plan which was developed with the help of a business expert that included: Executive Summary, Definition of the business, Product/Service Description, Market Research/Analysis, the Marketing Plan, Operations, Financial Data and investment required. Expenses were identified which included start up and operating costs.

With regards to insurance, the following were identified; liability (business and personal), Medical, Personal liability for assistants, Client medical coverage. Property coverage included building/Contents and equipment (trucks, electronics, etc.). Insurance also included loss of Income. Consideration was given to the following taxes; Self-employment, Social Security, Employer Identification number, sales franchise, income, unemployment. Regulations were adhered to during registration and this included; choosing a unique name for the business. Stating the registration and considering Laws/Deed restriction.

\subsection{Capacity Building in the Tamarinds Fruit Value Chain}

Propagation Research and training was done in KEFRIKitui nurseries and in selected farmers' fields. From $T$. indica cuttings or seeds, the entrepreneurs raised seedlings on their own farms. The capacity of the entrepreneurs was also built in nursery establishment. Processing and value addition of T.indica products was done first in KEFRIKarura laboratories, followed by trainings with the entrepreneurs in Kitui. After collecting fresh and ripe fruits, they were sorted out to remove dirt and discolored and physically deformed fruits. This was followed by washing and pulp extraction using pestle and mortar. This was used for making the following products; Tamarindus jam which was made by dissolving sugar in a pan of warm water and strained to remove impurities. $1 \mathrm{~kg}$ fruit pulp was mixed with gum Arabic preservative and stirred into the sugar solution. All the ingredients were boiled with constant stirring until uniformly thick. Lemon juice was added when the jam was near set. Tamarindus juice which was made by adding 1 teaspoon of Gum arabic preservative to $1 \mathrm{~kg}$ of fruit pulp. In a separate pan, sugar was dissolved in warm water then mixed with pulp mixture followed by straining using a muslin cloth. This was then boiled, pasteurized, poured in sterilized jars and heated before cooling, labeling and storing. Finally, Tamarindus wine which was made from $2 \mathrm{~kg}$ of the pulp that was weighed and mixed with water and boiled while stirring. The boiled pulp was left to cool and then sieved using a plastic sieve. The sieved product was then put in a container and $3 \mathrm{~kg}$ of honey was added followed by yeast, Gum arabic and then stirred properly. The product was left to ferment for 7 days and then sieved using a clean muslin cloth. The filtrate put in $2 \frac{1}{2}$ litre bottles, closed tightly and kept in a safe place for fermentation. Fermentation was left between one and two months to allow the wine to mature.

All the three products were packed in well labeled containers and taken to the Kenya Bureau of Standards for 
verification. The group was equipped with business, financing, management and communication skills to effectively source for raw materials, process their products and market them.

\section{Results and Discussion}

There is a wide range of raw materials that can be used for product development. This study was by no means exhaustive and enterprises like apiculture, sericulture, gums and resins, cultivation of medicinal plants were not covered. For the selected site, Kitui; attention is given to Tamarindus fruit products as indigenous fruit enterprise.

Matinyani group was formed in 2010 with a membership of 20. The name was chosen in consultation with the Ministry of Sports, Culture and Arts to avoid duplication. The membership has increased to 60 entrepreneurs who have received training in propagation, processing, value addition and marketing of Tamarindus jam, juice and wine. The group identified a business premise in the town center due to its accessibility by customers. With the help of a business plan, they are able to budget for both start up and operating costs, insurances and taxes that are due for the enterprise.

Among the benefits that have enhanced their livelihoods are; increased tree cover which can be used for firewood, shade, income from the selling of fresh fruits and value added products.

The participants were equipped with capacity to market well labeled and packaged products that are able to attract customers. They are now aware of their potential markets and can exhibit their products during trade exhibitions and Agricultural trade fairs. With knowledge on financial support services, they are now able to access credit facilities to enable them produce competitive products for the market.

Monitoring of the processing and quality of products by KEFRI has been going on through regular visits to the group. This is to ensure continuous processing and marketing of quality products according to the Kenya Bureau of Standards (KEBS); which is a Government organization whose aims and objectives include preparation of standards relating to products, measurements, materials, processes etc.

The cost for production of the juice, jam and wine from $\mathrm{T}$. indica by NBE was varied. The NBE incurred Ksh. 60.19, 172.71 and 263.51 to process 1 litre of juice, $1 \mathrm{~kg}$ of jam and 1 litre of wine (Table 2). Amongst the three products processed by NBE from $T$. indica, the most profitable was jam with a profit margin of Ksh. 127.29 from $1 \mathrm{~kg}$ of jam. The jam had the benefit cost ratio of 1.74, implying that out of investment of Ksh. 1, the NBE was able to recover the cost of investment and made an extra Ksh. 0.74 as profit.

Table 2. Cost of Investment and Returns from T. indica Products

\begin{tabular}{|c|c|c|c|c|c|c|}
\hline \multirow[b]{2}{*}{ Operation/inputs } & \multicolumn{2}{|c|}{ Juice } & \multicolumn{2}{|c|}{ Jam } & \multicolumn{2}{|c|}{ Wine } \\
\hline & Quantity & Cost & Quantity & Cost & Quantity & Cost \\
\hline Pulp & $500 \mathrm{~g}$ & 50 & $1 \mathrm{~kg}$ & 100 & $2 \mathrm{~kg}$ & 200 \\
\hline Water & $500 \mathrm{mls}$ & 0.25 & 1 litre & 0.5 & 2 litres & 1 \\
\hline Sugar & $500 \mathrm{~g}$ & 50 & & 100 & & 200 \\
\hline Honey & - & - & - & & $3 \mathrm{~kg}$ & - \\
\hline Gum arabic preservative & 1 teaspoon & 40 & & 40 & & 80 \\
\hline Yeast & - & - & - & - & $2 \mathrm{~kg}$ & 400 \\
\hline Lemon juice & 1 & 10 & 2 & 20 & 3 & 40 \\
\hline Fuelwood & 1 stack & 50 & 2 stacks & 100 & 3 stacks & 150 \\
\hline Labour & 2 man hour & 43.75 & & 43.75 & & 43.75 \\
\hline Plastic sieve & 1 large & 0.28 & 2 large & 0.56 & 3 large & 1.11 \\
\hline Muslin cloth & $1 / 2$ meter & 1.67 & 1 meter & 3.33 & 2 meter & 6.67 \\
\hline Jars & 1.00 & 25.00 & 2.00 & 50.00 & 3.00 & 75.00 \\
\hline Labels & 1.00 & 30.00 & 2.00 & 60.00 & 3.00 & 120.00 \\
\hline Total cost & & 300.94 & & 518.14 & & 1317.53 \\
\hline Unit Total cost & & 60.19 & & 172.71 & & 263.51 \\
\hline Returns & \multicolumn{2}{|c|}{ Juice } & \multicolumn{2}{|c|}{ Jam } & \multicolumn{2}{|c|}{ Wine } \\
\hline Physical outputs in containers & \multicolumn{2}{|c|}{5.00} & \multicolumn{2}{|c|}{3.00} & \multicolumn{2}{|c|}{5.00} \\
\hline Price/container & \multicolumn{2}{|c|}{100.00} & \multicolumn{2}{|c|}{300.00} & \multicolumn{2}{|c|}{300.00} \\
\hline Gross returns & \multicolumn{2}{|c|}{500.00} & \multicolumn{2}{|c|}{900.00} & \multicolumn{2}{|c|}{1500.00} \\
\hline Net returns & \multicolumn{2}{|c|}{199.06} & \multicolumn{2}{|c|}{381.86} & \multicolumn{2}{|c|}{182.47} \\
\hline Unit net returns & \multicolumn{2}{|c|}{39.81} & \multicolumn{2}{|c|}{127.29} & \multicolumn{2}{|c|}{36.49} \\
\hline Benefit cost ration & \multicolumn{2}{|c|}{1.66} & \multicolumn{2}{|c|}{1.74} & \multicolumn{2}{|c|}{1.14} \\
\hline
\end{tabular}




\section{Conclusions and Recommendations}

Matinyani Enterprise was set up after meeting set regulations by the Ministry of Sports, Culture and Arts. To improve their livelihood, their capacity was improved in indigenous fruit propagation, processing and value addition of Tamarindus fruit juice, wine and jam. They also acquired knowledge on requirements of the Kenya Bureau of Standards (KEBS) before registering their products. There are various indicators of adoptability of the technologies and improved livelihood among these group members; Increased awareness of sustainable utilization and conservation of Indigenous Fruit Trees (IFTs), Value added indigenous fruit products being sold locally, a merry go - round of finance lending among themselves. The group was able to make a daily gross earnings of Ksh. 8000 (US \$ 92) from raw flavored fruit pulp, Ksh. 12,000 (US \$ 138) from the juice, Ksh. 15,000- 20,000 (US \$ $172-230$ ) from the wine and Ksh. 10,000 from the jam. Among the three products, the jam was most profitable with a net return of Ksh. 127.29 from 1 $\mathrm{kg}$. As a result of the enterprise, group members have been able to pay school fees for their children, buy livestock, tree seedlings among other benefits. There is still a challenge adoptability of the propagation techniques due to the long periods indigenous fruits take to mature. There is therefore need for research to be fast - tracked in this area

\section{Acknowledgements}

We highly acknowledge KEFRI for the technical support towards this research, Dr. Linus Wekesa for his immense contribution in the cost and return structure for the Tamarindus fruit products and Mrs. Sheila Mbiru for her invaluable contribution to the content and editing of this paper.

\section{REFERENCES}

[1] International Labor Organization (ILO). The promotion of sustainable enterprises. International Labor Conference, $96^{\text {th }}$ session. International Labour office, Geneva, Switzerland. 2007.

[2] International Fund for Agricultural Development (IFAD). Rural Poverty. IFAD, Quintyl, Rome, Italy. 2011.
[3] World Resource Institute (WRI) in collaboration with United Nations Development Program and World Bank. World Resources: The wealth of the poor: Managing Ecosystems to fight poverty. Washington DC: WRI, 2008.

[4] I. Gordon, and W. Ayiemba. Harnessing butterfly biodiversity for improving livelihood and Forest Conservation: The Kipepeo Project. Journal of Environment and Development . No. 12(1), 82 - 98, 2003.

[5] C. S. Kumar and S. Bhattacharya. Tamarind seed: Properties, Processing and Utilization. Critical reviews in Food Science and nutrition. Vol. 48, pp. 1 - 20, 2008.

[6] E. De Caluwé, K. Halamová, and P. Van Damme.. Tamarindus indica L.: A Review of traditional uses, Phytochemistry and Pharmacology. Afrika focus Vol. 23, No. 5(1), $53-83,2010$.

[7] K. El - Siddig, H. P. M. Gunasena, B. A. Prasa, D. K. N. G.. Pushpakumara, K. V. R. Ramana, P. Vijayanand, J. T. Williams. Tamarind - Tamarindus indica L. Fruits for the future 1. Southampton Centre for underutilized crops, Southampton, UK, 188p, 2006.

[8] F. T. Y. Euphemia and S. L. C. Sian. The effect of retail service quality and product quality on customer loyalty. Journal of Database Marketing \& Customer Strategy Management Vol. 17, 222-240, 2010.

[9] PGRI - SAFORGEN. Review and Appraisal on the status of Indigenous fruits in East Africa. B. Chikamai, O. Eyog matig and $\mathrm{M}$. Mbogga. (eds.). A report in the framework of AFREA/FORNESSA. Pp.36, 2004.

[10] World Resource Institute (WRI) in collaboration with United Nations Development Program and World Bank. World Resources: Roots of resilience - Growing the wealth of the poor. Washington DC: WRI, 2005.

[11] C. Seixas and F. Berkes. Community - based enterprises: The significance of Partnerships and institutional linkages. International journal on commons Vol. 4(1), 1 - 7, 2009.

[12] J. Elliott and D. Simba. Conservation Enterprise: what works, where and for whom?. Gate keeper, F. Hall (ed.). IIED, p.2, 2011.

[13] S. Franzel, R. Kindt. Species priority setting procedures. In: I. Dawson, C. Harwood, R. Jamnadas, J. Beniest, eds. Agroforestry tree domestication: a primer. Nairobi: World Agroforestry Centre ICRAF, Kenya, 36 - 45, 2012.

[14] M. Anyonge - Bashir and P. udoto. Beyond Philanthropy: Community nature based Enterprises as a basis for wildlife conservation. The George Wright Forum, Vol. 29, No. 1, 67 73, 2012. 